\title{
NUCLEOTIDE SEQUENCE OF THE MACROMOMYCIN APOPROTEIN GENE AND ITS EXPRESSION IN STREPTOMYCES MACROMOMYCETICUS
}

\author{
Nobuo Sakata, Toshie Kanbe, Masahide Tanabe ${ }^{\dagger}$, \\ Hidemi Hayashi and MaKoTO HoRI \\ Showa College of Pharmaceutical Sciences, \\ 5-1-8 Tsurumaki, Setagaya-ku, Tokyo 154, Japan \\ Kunimoto HotTA \\ Department of Antibiotics, National Institute of Health, \\ 2-10-35 Kamiosaki, Shinagawa-ku, Tokyo 14I, Japan \\ Masa Hamada \\ Institute of Microbial Chemistry, \\ 3-14-23 Kamiosaki, Shinagawa-ku, Tokyo 141, Japan
}

(Received for publication August 2, 1989)

\begin{abstract}
A $1.6 \mathrm{~kb}$ Sph I - Sac I DNA fragment from Streptomyces macromomyceticus, expected to include the macromomycin (MCM) apoprotein gene, was sequenced. The fragment $(1,556 \mathrm{bp})$ was found to include a putative promoter, an ORF directing pre-apoprotein which should be split into the leader peptide $\left(\mathrm{Met}^{1}\right.$ to $\mathrm{Gly}{ }^{32}$ ) and the $\mathrm{MCM}$ apoprotein $\left(\mathrm{Ala}^{33}\right.$ to $\mathrm{Ala}^{144}$ ), and a putative terminator. The amino acid sequence deduced from the base sequence of the DNA is consistent with the amino acid sequence previously determined by the Edman degradation and other procedures applied to the protein, except base sequence AAC coding for Asn was found rather than Asp ${ }^{111}$ previously reported. The GC content of the 3rd letters throughout the ORF was $92 \%$ in contrast to the sum of the first and the second letters, $62 \%$. There was a low GC content stretch of $20 \mathrm{bp} \mathrm{(30 \%} \mathrm{GC)} \mathrm{at}$ about 120 bp upstream of the ORF. The $P_{S t}$ I - Sph I 620 bp fragment including the low GC content stretch showed promoter activity when subcloned in a promoter probe vector. About 700 nucleotides long mRNA, which is long enough to span the ORF and the bordering regions, was identified using the Northern blot analysis. A primer extension experiment showed that the transcriptional starting point was A at 89 bp upstream of the ORF. Dot blot analysis of expression of MCM apoprotein gene indicated that the gene was expressed nearly constitutively, while production of holo MCM (the complex consisting of MCM apoprotein and a specific chromophore) depended greatly on culture conditions.
\end{abstract}

Actinomycetes are known to produce a variety of biologically active secondary metabolites, such as antibiotics and enzyme inhibitors. Antibiotic-producing microorganisms are immune to killing effects of their own products (self-resistance) and it has been reported that a gene(s) responsible for self-resistance are commonly localized in a gene cluster including a set of genes which code for a series of enzymes involved in biosynthesis of the same antibiotic ${ }^{1,2)}$. The gene cluster of erythromycin biosynthesis, for example, has been cloned by following the self-resistance gene (ery ${ }^{r}$ ) of the producer strain ${ }^{3}$. Little is known, however, about antitumor antibiotics in respect to gene structures for their biosynthesis and

\footnotetext{
$\dagger$ Present address: Takara Shuzo Co., Ltd., Shimogyo-ku, Kyoto.
} 
self-resistance. Streptomyces macromomyceticus M480-M1 produces macromomycin (holo MCM) ${ }^{\dagger}$, a complex protein with antitumor activity ${ }^{4 \sim 6}$. Holo $\mathrm{MCM}$ consists of a protein part (MCM apoprotein whose amino acid sequence is known ${ }^{7)}$ ) and a noncovalently bound chromophore; the chromophore by itself causes DNA strand scission and has cytotoxicity ${ }^{8,9)}$ while MCM apoprotein has peptidase activity ${ }^{10}$ on its own and stabilizes the chromophore in the complex ${ }^{11}$. We initiated cloning and sequencing of the apoprotein gene in the hope that the study would give us clues to the following questions: 1) Is the gene expressed in concert with biosynthesis of the chromophore, i.e., in concert with holo MCM production? 2) Is the gene transcribed into a monocistronic mRNA or into a segment of a polycistronic mRNA which directs a set of proteins (enzymes) needed for biosynthesis of the chromophore? 3) Does putative precursor of the apoprotein have a leader peptide segment like other excretory proteins? 4) What is the molecular basis for self-resistance? The present paper deals with these problems. We have already reported details of cloning of a $2.6 \mathrm{~kb} S p h$ I - Sph I DNA fragment hybridizable to synthetic 50 mer probes which correspond to two regions of the amino acid sequence of MCM apoprotein ${ }^{12}$.

\section{Materials and Methods}

\section{Preparation and Analysis of RNA}

One $\mathrm{g}$ (wet weight) of mycelia, soon after harvest, was suspended in ice-cold $20 \mathrm{ml}$ of $5 \mathrm{M}$ guanidine monothiocyanate-10 mM EDTA-50 mM Tris- $\mathrm{HCl}, \mathrm{pH} 7.5-8 \%$ 2-mercaptoethanol, sonicated with a Branson Sonifier 350 at $0^{\circ} \mathrm{C}$ at 6 watts for 4 minutes, and treated as described in the manual of RNA extraction kit (Amersham, RPN1264) to prepare total cellular RNA.

For Northern blot analysis, a $10-\mu \mathrm{g}$ sample of the RNA was denatured at $90^{\circ} \mathrm{C}$ for 2 minutes in $20 \mu 1$ of $20 \mathrm{~mm}$ MOPS, pH 7.0 - $5 \mathrm{~mm} \mathrm{NaOAc}-1 \mathrm{~mm}$ EDTA - 50\% formamide - $2.2 \mathrm{~m}$ formaldehyde, submitted to formaldehyde $(0.66 \mathrm{M})$ agarose gel electrophoresi ${ }^{13}$ ) and the RNA fractions in the gel were transferred onto a nitrocellulose sheet (Schleicher and Schuell BA85) ${ }^{14}$. The sheet was subjected to prehybridization treatment with $50 \%$ formamide $-5 \times \mathrm{SSC}-50 \mathrm{~mm}$ sodium phosphate, $\mathrm{pH} 6.5-100 \mu \mathrm{g}$ per ml sermon sperm DNA - $10 \times$ DENHARDT's hybridization solution at $42^{\circ} \mathrm{C}$ for 16 hours, and then hybridization was performed using another hybridization solution of the same component but supplemented with a nick-translated probe (Pst I - BamHI $540 \mathrm{bp}$ fragment, $1.5 \times 10^{8} \mathrm{cpm} / \mu \mathrm{g}$, up to $10^{6} \mathrm{cpm} / \mathrm{ml}$ ). The sheet was washed twice with $2 \times \mathrm{SSC}$ at $65^{\circ} \mathrm{C}$ for 30 minutes, dried and submitted to autoradiography at $-80^{\circ} \mathrm{C}$ for 40 hours. For the dot blot analysis, the denatured RNA was serially diluted and filtered onto a nitrocellulose sheet using a BRL Hybridot apparatus. Prehybridization and hybridization were conducted as above.

A primer extension analysis was conducted basically as described ${ }^{15)}$, using the antisense DNA (5'GCATGTGAAAACTCCGTTGGGCGTGGGG3', purchased from Takara Shuzo Co., Ltd.) which was complementary to the sequence between 582 and 609 (Fig. 3), as primer. Twenty $\mu \mathrm{g}$ of RNA isolated as described above and $0.7 \mathrm{pmol}$ of the $\left[5^{\prime}-{ }^{32} \mathrm{P}\right] \mathrm{DNA}$ primer were hybridized at $60^{\circ} \mathrm{C}$ for 60 minutes and then at the room temperature for 90 minutes and subjected to the extension reaction with reverse transcriptase (BRL 8025SA M-MLVRT) at $42^{\circ} \mathrm{C}$ for 60 minutes. The extended DNA products were electrophoresed on a 7 - $\mathrm{M}$ urea $-8 \%$ polyacrylamide gel in parallel with the products of the dideoxy sequence reaction using the same primer.

\section{Results and Discussion}

\section{Analysis of DNA Sequence}

In the previous study ${ }^{12)}$, a $2.6 \mathrm{~kb} S p h$ I - Sph I fragment of the MCM producer's genome was shown to hybridize to the synthetic 50 mer oligonucleotide probes for MCM apoprotein gene and was cloned

$\uparrow$ In the present paper, the entire antibiotic is referred to as holomacromomycin (holo MCM) while the protein part alone as macromomycin apoprotein (MCM apoprotein). 
Fig. 1. Subcloning of MCM apoprotein gene and its franking regions.
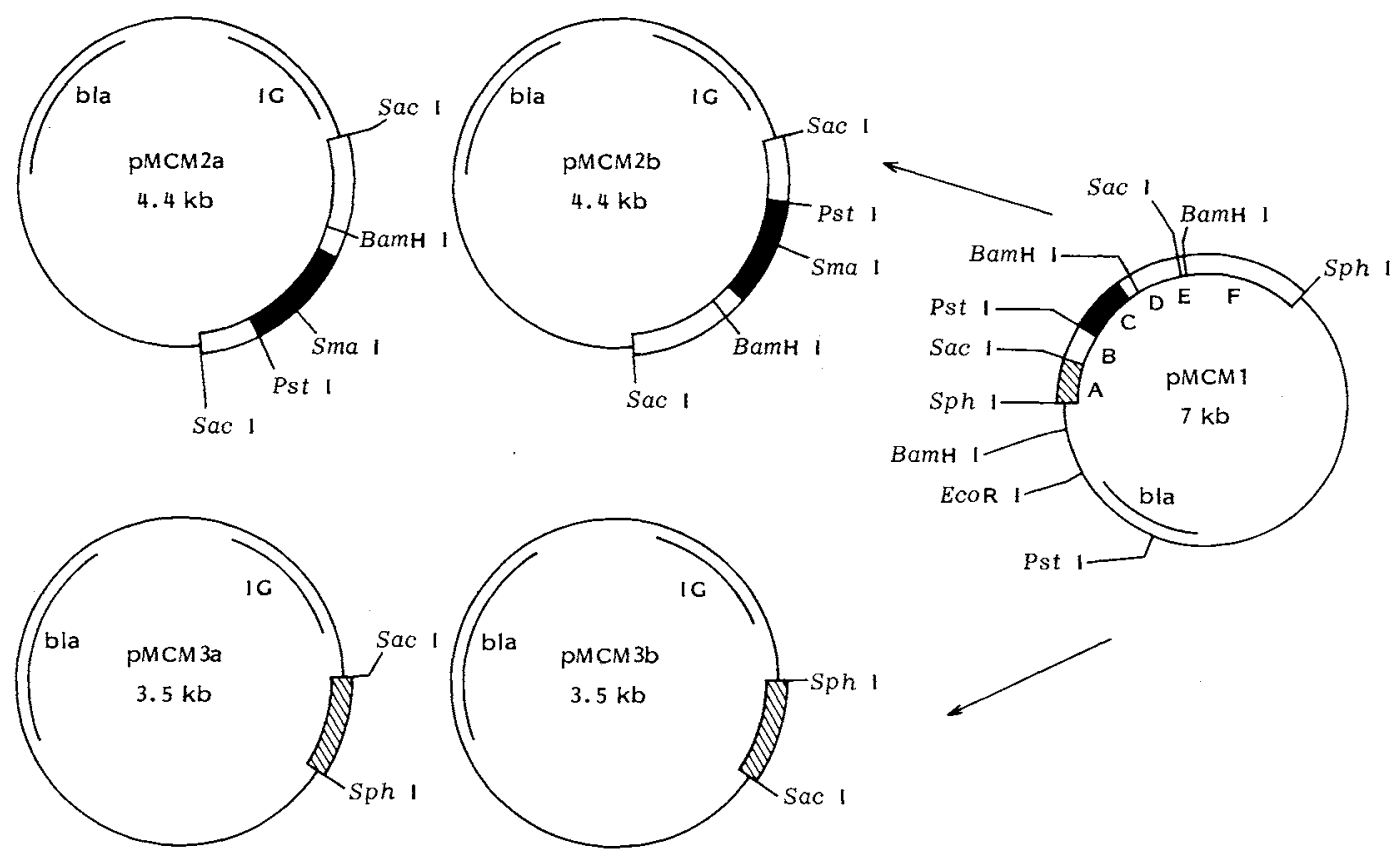

The solid box indicates ORF for pre-apoprotein. Top: pMCM2a and pMCM2b, derivatives of pUC118 ${ }^{27)}$ (a plasmid/phage chimeric vector), include $1.2 \mathrm{~kb}$ Sac I-Sac I fragment (B-C-D) in the opposite orientation to each other. Bottom: pMCM3a and pMCM3b, derivatives of pUC118 and pUC1 19 $9^{27)}$, respectively, include $S p h$ I - Sac I fragment (hatched box, the segment A) in the opposite orientation to each other. IG and bla are the intergenic region of M13 and a $\beta$-lactamase gene, respectively.

Fig. 2. Sequencing strategy and restriction map of the $1.6 \mathrm{~kb}$ Sph I-Sac I fragment from Streptomyces macromomyceticus.

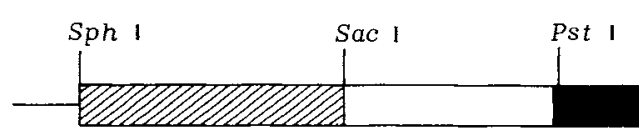

c

D

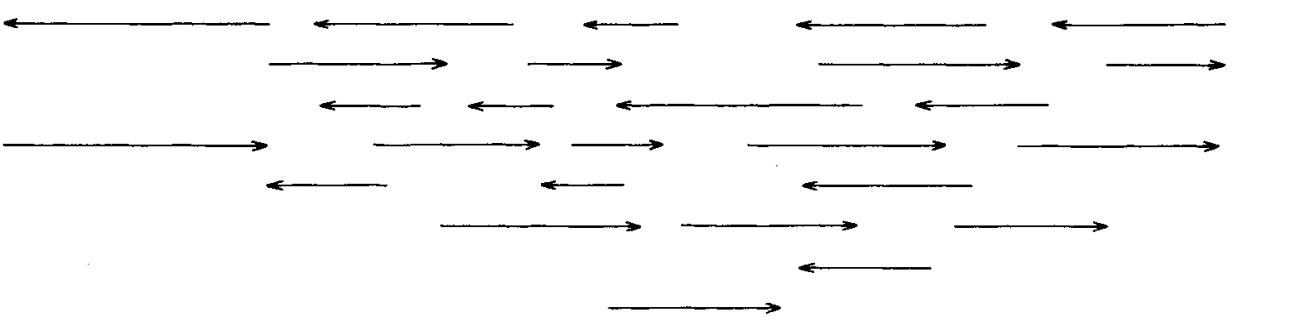

1,556 bp long

$$
\stackrel{100 \mathrm{bp}}{\longmapsto}
$$

Each arrow represents the length and orientation of a contiguous sequence determination. For the structural analysis of $\mathrm{B}-\mathrm{C}-\mathrm{D}$ region, $\mathrm{pMCM} 2 \mathrm{a}$ and $\mathrm{pMCM} 2 \mathrm{~b}$ were modified so that each derivative plasmid might have a deleted insert ${ }^{28)}$. In the dideoxy reactions ${ }^{29}$, dGTP was substituted by $\mathrm{dc}^{7} \mathrm{GTP}$ to eliminate several ambiguities ${ }^{30)}$. The solid box corresponds to the ORF for pre-apoprotein. 
Fig. 3. Nucleotide sequence of MCM apoprotein gene (mcmA) and deduced amino acid sequence.

$$
\begin{aligned}
& \text { Sph I } \\
& \text { 5. GCATGCCCGGGCTGGTGGAGAACGCGGCGACCACCGACGCGACACCGAACGCGGCGGCGC } \\
& 3^{\prime} \text { CGTACGGGCCCGACCACCTCTTGCGCCGCTGGTGGCTGCGCTGTGGCTTGCGCCGCCGCG } \\
& \text { ORF }-X \longrightarrow \\
& \text { 5. CGATGAGCAGCAGTTTGCGCGGCCGATGCGGTCGCCGAGGGTGCCCAIGGTGACCAGGAA } 120 \\
& \text { GCCGACGATCATGAAGCCGTAGATGTCCATGATCCACAGCTGCTGGGTCGCGTCCGCCTC } 180 \\
& \text { CAGGTCCACGGCCAGGTGCGGAaGCGCCAGGAGGAGAACGAAGACGTCGAGGGCCACGAG } 240 \\
& \text { CAGGGTGGGCAGgGCGAGGACCACGAGCCCCAGCCACTCCTTCCGCCCGGCCCTTTGTCC } 300 \\
& \begin{array}{c}
\text { SaC I } \\
\text { TICGCCAACAGTCATGTCCCTCAACTTTCCTCGTGAGCTCGGCAGGCCGGTCGCCTCACG }
\end{array} \\
& \text { CCCGGCACGCAGGAATACACCGGAGCGTTCCACGCTGCCAAAGCGGAGCCACATCTTGCT } 420 \\
& \text { GCGTGCTGTCTT TGGCGATCCGGGAACTCACCTGCGTITGCGGCATAGCAATTTCGAAGA } 480
\end{aligned}
$$

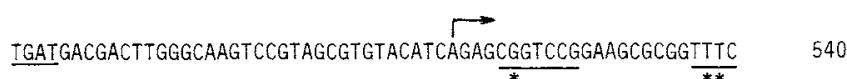

$$
\begin{aligned}
& \text { CCCTTGGGGAGGCCTCACCGGTCCGCATTTGTCCGCCATTICCCCACGCCDAACGGAGTT } 600 \\
& \text { momA gene } \\
& \text { Pst I } \\
& \text { TTCACATGCTGCAGAACACGTCTCGTTTCCTTGCCCGCGCCGGTGCCACCGTCGGCGTCG } 660 \\
& M L Q N \text { T S R F L A R A G A T V G V } 18 \\
& \text { CCGCCGGACTCGCCTTCAGCCTTCCAGCCGACCGCGATGGCGCGCCCGGTGTCACGGTGA } 720 \\
& \text { CGCCCGCCACGGGCCTGTCCAACGGCCAGACGGTGACCGTCTCCGCCACCGGGCTGACCC } 780 \\
& T P A T G L S N G Q T V T V S A T G L T \\
& \text { STma I } \\
& \text { CGGGGACCGTCTACCACGTGGGCCAGTGTGCGGTCGTGGAGCCGGGCGTCATCGGCTGTG } 840 \\
& \begin{array}{lllllllllllllllllll}
P & G & V & Y & H & V & G & Q & C & A & V & V & E & G & V & I & G & C & 78
\end{array} \\
& \text { ACGCGACGACCTCCACCGACGTCACCGCCGACGCCGCCGGCAAGATCACCGCCCAATTGA } 900 \\
& \text { AGGTGCACTCCTCGTJCCAGGCCGTGGTCGGCGCCAACGGCACGCCGTGGGGCACGGTCA } 960 \\
& \begin{array}{lllllllllllllllllllll}
K & V & H & S & S & F & Q & A & V & V & G & A & N & G & T & P & W & G & T & V & 118
\end{array} \\
& \text { ACTGCAAGGTCGTCAGCTGCTCGGCGGGGCTCGGCAGCGACTCCGGTGAGGGCGCCGCCC } 1,020 \\
& \text { N C K V V S S C S A G L G S D S G E G A A } 138 \\
& \text { AGgCGATCACCTTCGCCTAGCCGgCACCTCTTACCAGgTCGCCACCCTCGCCCGGACATG } 1,080 \\
& \text { Q A I T F A Ter } \\
& \text { Sat I } \\
& \text { ACGAAGCGGGTCGGGCCGCGGTCTITTTCCCCGCACGCAGTCGACCCGCCTCATGTCATGT } \\
& \text { BamH I } \\
& \text { CCCTGACAGGATCCTCGCATCAGACCTGCGGTACCGCCCCGCCGCGACÁtCGCGCGAACC } \quad 1,200 \\
& \text { Sal I } \\
& \text { GCCCGGCCGGGTCGACGCGTTCGCACCCGCGCCACCGCCGCCGCCTGGTCCGCGCCCAGA } \quad 1,260 \\
& \text { TGCCGCTECGGCCGCCGGGCGTTCTCCACCAGGCTGGGCAGCGTGAACCCGGTGTCCCAC } \quad 1,320 \\
& \text { GGCTGAAGTGCCTCACGGACCCGGTCGCAGTGCTCCTCCAGCGCCGCCACCGTCACCGTG } 1,380 \\
& \text { CCGAACGCGGGCCCCGATCCCATGTACGCGTACGAGGCGTCCACCGGTTGAGCACCCGCC } \quad 1,440 \\
& \text { CGCCGGTCGCCACCGCGAACGCCGCCGAGCTGCCGCAGGCGAGCGGCCACCAGCGGGGAC } \quad 1,500 \\
& \text { Sac I } \\
& \text { TTGGAACCCTCGCCCACCACGTCGAGGAACGGCGCCGCGCCGTCGCCGCCGAGCTC 3. }
\end{aligned}
$$

ORF-X starts at GTG $(34 \sim 32)$ in the opposite orientation. Underlines with arrowheads indicate inverted repeat. Low GC\% stretch is underlined. The bent arrow at 517 indicates the transcriptional start point (see Fig. 4). Underlines with single and double asterisks indicate direct repeated sequences. SD sequence is boxed. Apoprotein sequence starts with the marked L ( $\mathrm{Ala}^{33}$ ). Five T's are underlined with triple asterisks. 
into pBR322 to give pMCM1. In the present study, the insert was subcloned as shown in Fig. 1 and the A to $\mathrm{D}$ regions of the insert were sequenced using the strategy outlined in Fig. 2. The resulting 1,556 bp sequence shown in Fig. 3 turned out to include an ORF corresponding to MCM pre-apoprotein which should be split into a leader peptide ( $\mathrm{Met}^{1}$ to $\mathrm{Gly}^{32}$ ) and $\mathrm{MCM}$ apoprotein ( $\mathrm{Ala}^{33}$ to $\mathrm{Ala}^{144}$ ). The initiator ATG of this ORF which is preceded by $\mathrm{C}$, is a typical initiator of Streptomyces genes ${ }^{16)}$. The amino acid sequence determined in the conventional method including Edman degradation and other methods applied to the purified protein ${ }^{73}$ was found to be correct except $A \mathrm{sp}^{111}$ where DNA sequencing showed AAC which codes for Asn rather than Asp. The GC content of the 3rd letters throughout the ORF was $92 \%$ while that of the sum of the 1 st and 2 nd letters was $62 \%$, in good agreement with the data of the other ORFs of actinomycetes ${ }^{17 \sim 24)}$. The leader peptide appeared to be a typical one, containing Gln, Asn and basic amino acids ( 2 Arg's in this case) in the first $1 / 3$ region, while containing Ala, Gly and hydrophobic amino acids, such as Val and Leu, in the latter $2 / 3$ region. The AACGGAG, which preceded the starter ATG with a $7 \mathrm{bp}$ space, should be the SD box for the ORF. The $150 \mathrm{bp}$ upstream region adjacent to the starter ATG had low GC content ( $58 \%$ ) and includes two repeated heptamers (CGGTCCG starting at 521 and 558, TTTCCCC starting at 537 and 575). Near the upstream end of this region, there was a $20 \mathrm{bp}$ stretch (465 484) whose GC content was unusually low $(30 \%)$. The low GC content suggests the presence of a promoter in this neighborhood. The transcriptional start point was determined as $\mathrm{A}$ at 517 , as shown in Fig. 4, suggesting that ATGACG (483 488) and TAGCGT (504 509) may function like Escherichia coli -35 and -10 regions, respectively, although the former was located centering at -31 rather than -35 .

Fig. 4. Primer extension experiment for identification of transcriptional start point.

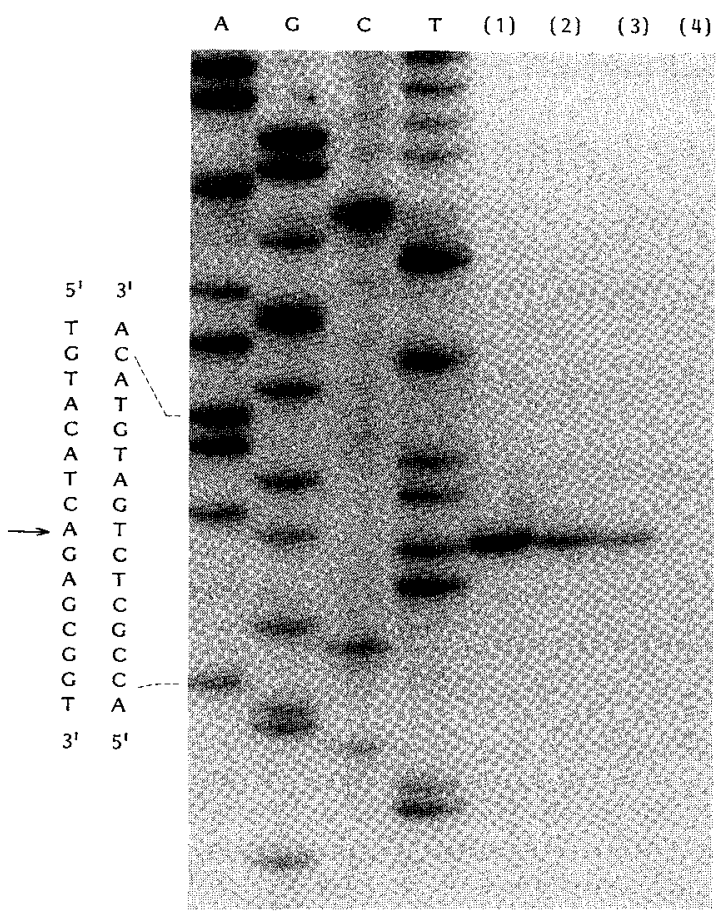

The amount of reverse transcriptase in a reaction mixture was varied; (1) 40 units, (2) 30 units, (3) 20 units, (4) 0 unit. The arrow indicates the starting A. For details, see "Materials and Methods". 
The five consecutive T's found at about $60 \mathrm{bp}$ behind the stop codon (TAG) seems to be equivalent to the rho factor-independent transcription terminator of $E$. coli ${ }^{25}$. However, no sequence for a hairpin structure was preceding the five T's, inconsistent with the termination signal of $E$. coli. The presumptive promoter and terminator for transcription of this gene were confirmed by the promoter activity of the upstream region and by the size of mRNA (see below). Near the upstream end of the $1,556 \mathrm{bp}$ segment, a neighboring ORF appeared to start with GTG in the opposite direction. The 3rd letters of codons in frame of the GTG were all $\mathrm{G}$ or $\mathrm{C}$.

\section{Expression of MCM Apoprotein Gene}

Northern blot analysis of the gene transcript indicated that MCM apoprotein gene was transcribed into an about 700 nucleotides long mRNA, as shown in Fig. 5. Considering the size of the ORF for the pre-apoprotein ( $435 \mathrm{bp}$ ), the size of the mRNA strongly suggested that MCM apoprotein gene was transcribed as a monocistronic mRNA, under the control of its own promoter and terminator. Consistent with this possibility, some base sequences characteristic of promoter and terminator were found in the upstream and downstream flanking regions, respectively (Fig. 3), as discussed above. Promoter activity of the upstream segment spanning the regions A-B (Fig. 1) was tested by integrating the segment into a promoter probe vector, transfecting Streptomyces lividans protoplasts with the resulting plasmids, and determining the expression of the marker gene neo ${ }^{\mathrm{r}}$, as shown in Fig. 6. Promoter activity was evident with clones incorporating the plasmid pIJ486 A-B in which the A-B segment was in the orientation of A-B $\cdot$ neo $^{\mathrm{r}}$ (Fig. 6 , left $e$ and $f$ ). The segment A-B, when inserted into the vector in the opposite orientation, also showed promoter activity (Fig. 6, left c and d), which was an unexpected finding. A possible promoter for the ORF-X, which should work towards the ORF$X$, might have exerted its influence toward the expression of the marker gene.

We next asked if this gene would be expressed in concert with biosynthesis of the chromophore. Since the chromophore alone but not the apoprotein alone is cytotoxic ${ }^{89}$, biosynthesis of the chromophore can be approximately followed by determining antibacterial titer (vs. Micrococcus lysodeikticus) of fermentation broths. The MCM producer strain was grown in "productive medium" (see legend to Fig. 5) or "nonproductive medium" (see legend to Fig. 7) and antibacterial titers of broth filtrates were followed with cultivation time, along with expression of the apoprotein gene determined by dot blot analysis. Fermentation in "productive medium" resulted in appreciable antibacterial activity around day-4, as opposed to no sign of the activity in "nonproductive medium" at any stage of

Fig. 5. Northern blot analysis of MCM apoprotein gene transcript.

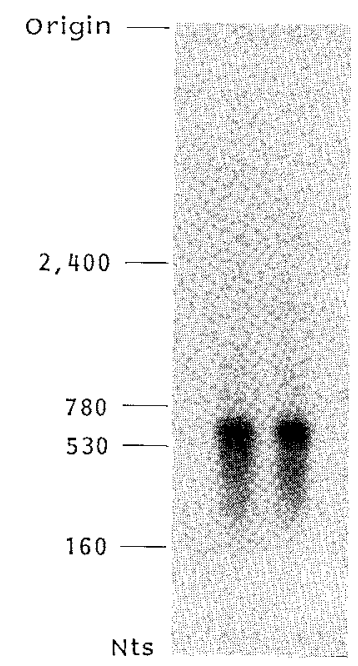

The producer strain was grown in a medium allowing semioptimum production of MCM (referred to as "productive medium", the same medium as previously reported ${ }^{4}$ except that insoluble materials were removed before autoclaving). Extraction and analysis of RNA were conducted as described in "Materials and Methods". Results of duplicated electrophoresis are shown. Mixing the sample with RNase, but not DNase, before electrophoresis resulted in disappearance of the hybridized spot. Numbers indicate mobility of size marker RNAs (BRL). 
Fig. 6. Promoter activity of $P$ st I - Sph I $620 \mathrm{bp}$ fragment.
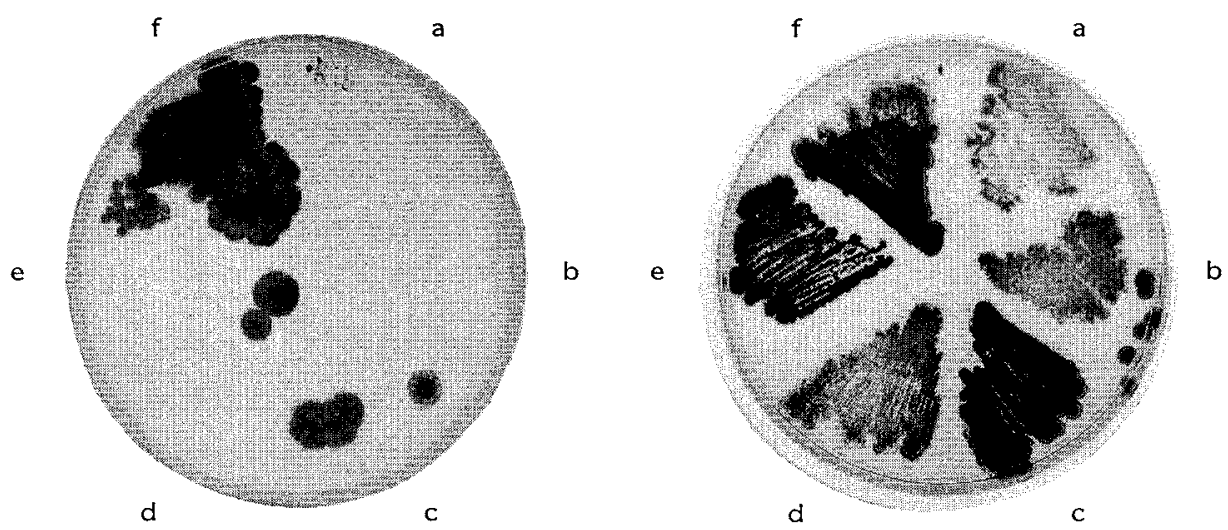

Sph I - Pst I 620 bp fragment (A-B segment, see Fig. 2) was inserted into a promoter probe vector (pIJ486 ${ }^{31)}$ ) to make pIJ486-A-B and pIJ486 $\cdot \mathrm{B}-\mathrm{A}$ in which the orientation of the insert to the marker gene $\left(\right.$ neo $^{\mathrm{r}}$ ) was A-B $\cdot$ neo $^{\mathrm{r}}$ and $\mathrm{B}-\mathrm{A} \cdot$ neo $^{\mathrm{r}}$, respectively. Streptomyces lividans TK 21 was transformed with these plasmids. Clones were isolated, smeared on ISP-No. 2 plates including either $15 \mu \mathrm{g} / \mathrm{ml}$ of ribostamycin (left) or no antibiotic (right), and allowed to grow at $30^{\circ} \mathrm{C}$ for a week. Clones tested are (a) S. lividans TK21/pIJ486, (b) S. lividans TK21, (c) S. lividans TK21/pIJ486·B-A clone 1, (d) S. lividans TK21/pIJ486 B-A clone 2, (e) $S$. lividans TK2I/pIJ486 A-B clone 1, (f) $S$. lividans TK21/pIJ486 A-B clone 2 . Each clone was confirmed to retain unaltered structure of the plasmid and the DNA insert.

Fig. 7. Correlation between expression of the apoprotein gene and biosynthesis of the chromophore.

(A)

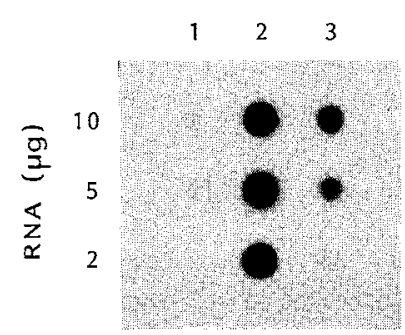

(B)

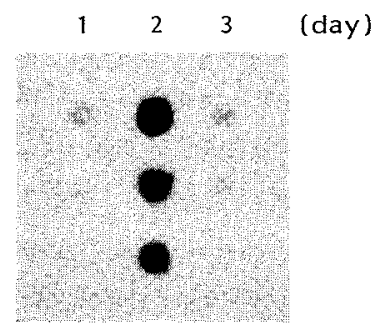

Streptomyces macromomyceticus M480-M1 was grown either in a nonproductive medium (Tryptic Soy Broth, Difco 0370-101-1) (A) or in the productive medium (see the legend to Fig. 5) (B). In the nonproductive medium, biosynthesis of the chromophore was undetectable (see text). Cells were harvested on day-1, 2 and 3, the total RNA was prepared therefrom and the apoprotein gene transcript was quantitated by dot blot analysis using nick-translated 540 bp Pst I - BamH I fragment (C region, see Fig. 2) as the probe. The film was exposed at $-80^{\circ} \mathrm{C}$ for 40 hours.

fermentation, although the producer cells grew faster in the latter medium (data not shown). In contrast, MCM apoprotein gene was transcribed in "nonproductive medium" as well as in "productive medium", around day-2, the middle of the growth phase, as shown in Fig. 7. In addition, S. macromomyceticus CHR-1 $1^{\dagger}$, a mutant giving no antibacterial titer in any fermentation medium, also transcribed the apoprotein gene into an mRNA of unaltered size. The Southern blot analysis of the genome of this mutant revealed that there was no detectable change in the structure of MCM apoprotein gene and its neighborhood (data

+ Kindly supplied by Dr. N. NAOr, Kanegafuchi Chemical Industry Co., Ltd. This mutant, selected for its strong resistance to holo $\mathrm{MCM}$ in an attempt to obtain highly productive strains, was thought to produce an excess amount of the apoprotein but not the chromophore (personal communication). 
not shown). The constitutive expression of MCM apoprotein gene, without any correlation with biosynthesis of the chromophore, strongly suggests that the apoprotein is not a secondary metabolite but an important protein playing some physiological role for the cells with its aminopeptidase activity. It must be fortunate for the MCM producer cells that this excretory protein has affinity to the toxic product of the accidentally imported genes. No use of TTA for any Leu residues in the MCM apoprotein gene may be another proof indicating that MCM apoprotein is not a secondary metabolite ${ }^{26)}$.

\section{Acknowledgment}

The authors are grateful to late Prof. H. UMEZAWA for his encouragement. We thank. Drs. N. NAOr and S. MIZUSAWA for helpful advice. The technical assistance of Miss M. IIYAMA and A. FUWA and Mr. S. IKENO is gratefully acknowledged.

\section{References}

1) Chater, K. F. \& C. J. BRuton: Resistance, regulatory and production genes for the antibiotic methylenomycin are clustered. EMBO J. 4: 1893 1897, 1985

2) Ohnuki, T.; T. Imanaka \& S. Aiba: Self-cloning in Streptomyces griseus of an str gene cluster for streptomycin biosynthesis and streptomycin resistance. J. Bacteriol. 164: 85 94, 1985

3) Stanzak, R.; P. Matsushima, R. H. Baltz \& R. N. Rao: Cloning and expression in Streptomyces lividans of clustered erythromycin biosynthesis genes from Streptomyces erythreus. Biotechnology 4: 229 232, 1986

4) Chimura, H.; M. Ishizuka, M. Hamada, S. Hori, K. Kimura, J. Iwanaga, T. Takeuchi \& H. Umezawa: A new antibiotic, macromomycin, exhibiting antitumor and antimicrobial activity. J. Antibiotics 21: 44 49, 1968

5) Lippman, M. M.; W. R. Laster, B. J. Abbott, J. Venditti \& M. Baratta: Antitumor activity of macromomycin B (NSC 170105) against murine leukemias, melanoma and lung carcinoma. Cancer Res. 35: 939 945, 1975

6) Hidaka, T.; Y. Yano, T. Yamashita \& K. Watanabe: Biological activity of macromomycin. J. Antibiotics 32: $340 \sim 346,1979$

7) Samy, T. S. A.; K.-S. Hahn, E. J. Modest, G. W. Lampman, H. T. Keutmann, H. Umezawa, W. C. Herlihy, B. W. Gibson, S. A. CARR \& K. Biemann: Primary structure of macromomycin, an antitumor antibiotic protein. J. Biol. Chem. 258: 183 191, 1983

8) SuzuKi, H.; K. Miura, Y. Kumada, T. TAKeuChi \& N. TANAKa: Biological activity of non-protein chromophores of antitumor protein antibiotics: Auromomycin and neocarzinostatin. Biochem. Biophys. Res. Commun. 94: $255 \sim 261,1980$

9) NaOI, N.; Y. Kumada, T. Yamashita, T. TAKeuchi \& H. UmEZawa: DNA strand scission of methanol-extracted chromophores of macromomycin and auromomycin. J. Antibiotics 35: 934 936, 1982

10) ZAHEER, A.; S. ZAHEER \& R. MONTGOMERY: Peptidase activity of macromomycin apoprotein. J. Biol. Chem. 260: $11787 \sim 11792,1985$

11) NaOI, N.; T. Miwa, T. Okazaki, K. Watanabe, T. Takeuchi \& H. UmeZawa: Studies on the reconstitution of macromomycin and auromomycin from the chromophore and protein moieties. J. Antibiotics 35: 806 813, 1982

12) Hori, M.; N. Sakata, Y. Nino, O. Makabe, M. Hamada, S. Mizuno \& K. Hotta: Cloning of macromomycin apoprotein gene from Streptomyces macromomyceticus by use of 50 -mer deoxynucleotide probes. J. Antibiotics 41 : $1462 \sim 1470,1988$

13) Lehrach, H.; D. Diamond, J. M. Wozney \& H. BoedtKer: RNA molecular weight determinations by gel electrophoresis under denaturing conditions, a critical reexamination. Biochemistry 16: 4743 4751, 1977

14) SELden, R. F.: Analysis of RNA by Northern hybridization. In Current Protocols in Molecular Biology. Ed., F. M. Ausubel et al., pp. $491 \sim 498$, J. Wiley \& Sons, Inc., 1989

15) Jones, K. A.; K. R. Yamamoto \& R. Trian: Two distinct transcription factors bind to the HSV thymidine kinase promoter in vitro. Cell 42: $559 \sim 572,1985$

16) BIBB, M. J. ; M. J. BIBB, J. M. WARD \& S. N. CoHEN: Nucleotide sequences encoding and promoting expression of three antibiotic resistance genes indigenous to Streptomyces. Mol. Gen. Genet. 199: 26 36, 1985

17) Thompson, C. J. \& G. S. Gray: Nucleotide sequence of a streptomycete aminoglycoside phosphotransferase gene and its relationship to phosphotransferases encoded by resistance plasmids. Proc. Natl. Acad. Sci. U.S.A. 80: $5190 \sim 5194,1983$

18) Bernan, V.; D. Filpula, W. Herber, M. Bibb \& E. Katz: The nucleotide sequence of the tyrosinase gene from Streptomyces antibioticus and characterization of the gene product. Gene 37: 101 110, 1985

19) Distler, J.; C. Braun, A. Ebert \& W. Piepersberg: Gene cluster for streptomycin biosynthesis in Streptomyces 
griseus: Analysis of a central region including the major resistance gene. Mol. Gen. Genet. 208: 204 210, 1987

20) Hoshiko, S.; O. Makabe, C. Nojiri, R. Katsumata, E. Satoh \& K. Nagaoka: Molecular cloning and characterization of the Streptomyces hygroscopicus alpha-amylase gene. J. Bacteriol. 169: 1029 1036, 1987

21) Horinouchi, S; K. Furuya, M. Nishiyama, H. Suzuki \& T. Beppu: Nucleotide sequence of the streptothricin acetyltransferase gene from Streptomyces lavendulae and its expression in heterologous hosts. J. Bacteriol. 169: 1929 1937, 1987

22) Tohyama, H.; Y. Okami \& H. UmeZawa: Nucleotide sequence of the streptomycinphosphotransferase and amidinotransferase genes from Streptomyces griseus. Nucleic Acids Res. 15: 1819 1833, 1987

23) Nagaso, H.; S. SaIto, H. Sarto \& H. TaKahashr: Nucleotide sequence and expression of a Streptomyces griseosporeus proteinaceous alpha-amylase inhibitor (haimII) gene. J. Bacteriol. 170: 4451 4457, 1988

24) Aota, S.-I.; T. Gojobori, F. Ishibashi, T. Maruyama \& T. IKemura: Codon usage tabulated from the genebank genetic sequence data. Nucleic Acids Res. 16: r315 r405, 1988

25) Lewin, B. (Ed.): In Control at Termination. Genes 3rd Ed. pp. $248 \sim 251$, J. Wiley \& Sons Inc., 1987

26) Chater, K. F.; E. J. Lawlor, C. Mendez, C. J. Bruton, N. K. Davis, K. Plaskitt, E. P. Guthrie, B. L. Daly, H. A. BAylis \& K. VU Trong: Gene expression during Streptomyces development. In Biology of Actinomycetes '88. Ed., Y. OKAMI et al., pp. 64 70, Japan Scientific Societies Press, 1988

27) Vieira, J. \& J. Messing: Production of single-stranded plasmid DNA. In Methods in Enzymology. Vol. 153. Eds., R. Wu \& L. Grossman, pp. $3 \sim 11$, Academic Press, 1987

28) HeNikoff, S.: Unidirectional digestion with exonuclease III creates targeted breakpoints for DNA sequencing Gene 28: $351 \sim 359,1984$

29) Sanger, F.; S. Nicklen \& A. R. Coulson: DNA sequencing with chain-terminating inhibitors. Proc. Natl. Acad. Sci. U.S.A. 74: 5463 5467, 1977

30) Mizusawa, S.; S. Nishimura \& F. SeEla: Improvement of the dideoxy chain termination method of DNA sequencing by use of deoxy-7-deazaguanosine triphosphate in place of dGTP. Nucleic Acids Res. 14: 1319 1324, 1986

31) WARD, J. M.; G. R. JANSSEN, T. KIESER, M. J. BibB, M. J. BUtTNER \& M. J. BiBB: Construction and characterization of a series of multi-copy promoter-probe plasmid vectors for Streptomyces using the aminoglycoside phosphotransferase gene from Tn5 as indicator. Mol. Gen. Genet. 203: 468 478, 1986 